\title{
An interlaboratory comparison of techniques for extracting and analyzing trapped gases in ice cores
}

\author{
Todd Sowers $^{1}$, Ed Brook ${ }^{2,3}$, David Etheridge ${ }^{4}$, Thomas Blunier ${ }^{5}$, Andreas Fuchs ${ }^{5}$, \\ Markus Leuenberger ${ }^{5}$, Jerome Chappellaz ${ }^{6}$, Jean Marc Barnola ${ }^{6}$, Martin Wahlen 7 , \\ Bruce Deck ${ }^{7}$, and Connie Weyhenmeyer ${ }^{7}$
}

\begin{abstract}
We undertook an interlaboratory comparison of techniques used to extract and analyze trapped gases in ice cores. The intercomparison included analyses of standard reference gases and samples of ice from the Greenland Ice Sheet Project 2 (GISP2) site. Concentrations of $\mathrm{CO}_{2}, \mathrm{CH}_{4}$, the $\delta^{18} \mathrm{O}$ of $\mathrm{O}_{2}$, the $\delta^{15} \mathrm{~N}$ of $\mathrm{N}_{2}$, and the $\mathrm{O}_{2} / \mathrm{N}_{2}$, and $\mathrm{Ar} / \mathrm{N}_{2}$ ratios were measured in air standards and ice core samples. The standard reference scales for $\mathrm{CO}_{2}$ and $\mathrm{CH}_{4}$ were consistent at the $\pm 2 \%$ level. The $\delta^{\mathrm{O}_{2}} / \mathrm{N}_{2}$ and $\delta^{18} \mathrm{O}$ of $\mathrm{O}_{2}$ measurements showed substantial deviations between the two laboratories able to measure these ratios. The deviations are probably related to errors associated with calibration of the working standards. The $\delta^{A r} / \mathrm{N}_{2}$ and $\delta^{15} \mathrm{~N}$ of $\mathrm{N}_{2}$ measurements were consistent. Five laboratories analyzed the $\mathrm{CH}_{4}$ concentration in a 4.2-m section of the GISP2 ice core. The average of 20 discrete $\mathrm{CH}_{4}$ measurements was $748 \pm 10$ parts per billion by volume (ppbv). The standard deviation of these measurements was close to the total analytical uncertainty associated with the measurements. In all cases, those laboratories employing a dry extraction technique determined higher $\mathrm{CH}_{4}$ values than laboratories using a wet extraction technique. The origin of this difference is unclear but may involve uncertainties associated with blank corrections. Analyses of the $\mathrm{CO}_{2}$ concentration of trapped gases showed extreme variations which cannot he explained by analytical uncertainties alone. Three laboratories measured the $\left[\mathrm{CO}_{2}\right]$ on 21 discrete depths yielding an average value of $283 \pm 13$ parts per million by volume (ppmv). In this casc, the standard deviation was roughly a factor of 2 greater than the analytical uncertainties. We believe the variability in the measured $\left[\mathrm{CO}_{2}\right]$ results from impurities in the ice which may have compromised the $\left[\mathrm{CO}_{2}\right]$ of trapped gases in Greenland ice.
\end{abstract}

\section{Introduction}

The first studies of the composition of trapped gases in polar ice were performed in the 1950s [Scholander et al., 1956]. Since that time, numerous studies have focused on reconstructing the composition of the atmosphere from polar ice cores (see Raynaud et. al., 1993 for a recent review of the greenhouse gas records). Results of these studies suggest that atmospheric $\mathrm{CO}_{2}$ and $\mathrm{CH}_{4}$ levels were substantially lower

\footnotetext{
'Department of Gcosciences, Pennsylvania State University, University Park.

${ }^{2}$ Graduate School of Oceanography, University of Rhode Island, Narragansett.

${ }^{3}$ now at Department of Geology and Department of Environmental Science,Washington State University, Vancouver.

${ }^{4}$ Division of Atmospheric Research, Commonwealth Scientific and Industrial Research Organization, Aspendale, Victoria, Australia.

${ }^{5}$ Physics Institute, University of Bern, Switzerland.

${ }^{6}$ Laboratoire de Glaciologie et Geophysique de l'Environnement, CNRS, St Martin d'Heres, France.

${ }^{7}$ Scripps Institution of Oceanography, University of California, San Diego, La Jolla.
}

Copyright 1997 by the American Geophysical Union.

Paper number $97 \mathrm{JC} 00633$

0148-0227/97/97JC-00633\$09.00 during glacial periods than during interglacial periods [Neftel et al., 1985; Stauffer et al., 1985; Barnola et al., 1987; Neftel et al., 1988; Stauffer et al., 1988; Barnola et al., 1991; Blunier et al., 1993; Chappellaz et al., 1993; Chappellaz et al., 1993; Anklin et al., 1995; Barnola et al., 1995; Blunier et al., 1995] Such results have led to a number of biogeochemical studies designed to understand the nature of the concentration variations and their climatic significance. Given the importance of these records, we believe it is important to continually strive to increase the integrity of the paleoatmospheric records derived from data on the trapped gases in ice cores.

There are a number of factors to consider when reconstructing the composition of the paleoatmosphere from trapped gases in ice cores. After a core has been retrieved from the field and transported to the laboratory, the fossil air must be separated from the ice matrix for analysis. The composition of the air must be determined relative to a standard that has previously been calibrated on an acceptable concentration scale. The measured composition must be corrected for the effect of air enclosure in order to determine the composition of the atmosphere at the time the gases were occluded in the firn-ice region of the glacier. These corrections include gravitational and isotopic fractionation resulting from the diffusion of air in the firn layer above the 
Table 1. Listing of Laboratory Techniques Used to Extract Gases From Ice Cores, the Analytical Instrumentation Applied to the Extracted Fossil Air Samples, the Resulting Procedural Blank, and the External Precision

\begin{tabular}{|c|c|c|c|c|}
\hline & \multicolumn{3}{|c|}{ Elemental Analyses } & \multirow{2}{*}{$\begin{array}{l}\text { Isotopic Analyses } \\
\delta^{15} \mathrm{~N} \text { of } \mathrm{N}_{2} \\
\delta^{18} \underline{\mathrm{O} \text { of } \mathrm{O}_{2}}\end{array}$} \\
\hline & $\mathrm{CO}_{2}$ & $\mathrm{CH}_{4}$ & $\begin{array}{l}\delta \mathrm{Ar} / \mathrm{N}_{2} \\
\delta \mathrm{O}_{2} / \mathrm{N}_{2}\end{array}$ & \\
\hline Method & $\begin{array}{l}\text { cheese grater } \\
+\mathrm{GC}\left(\text { as } \mathrm{CH}_{4}\right)\end{array}$ & $\begin{array}{l}\text { CSIRO } \\
\text { cheese grater } \\
+ \text { GC }\end{array}$ & \multirow[t]{4}{*}{ N/A } & \multirow[t]{4}{*}{ N/A } \\
\hline Blank & $0.8 \mathrm{ppm}^{\mathrm{b}}$ & $5 \mathrm{ppb}^{\mathrm{c}}$ & & \\
\hline External precision ${ }^{d}$ & $\pm 1.2 \mathrm{ppm}$ & $\pm 5 \mathrm{ppb}$ & & \\
\hline Size of ice sample & $0.5-1.5 \mathrm{~kg}$ & $0.5-1.5 \mathrm{~kg}$ & & \\
\hline Method & \multirow[t]{3}{*}{ N/A } & $\begin{array}{l}\quad \text { Bern } \\
\text { small mill device } \\
+\mathrm{GC}\end{array}$ & $\begin{array}{l}\text { milling device } \\
\text { mass spectrometry }\end{array}$ & \multirow{5}{*}{$\begin{array}{l}\text { milling device } \\
\text { mass spectrometry } \\
\text { blank }<0.1 \% \text { o } \\
\delta^{15} \mathrm{~N} \pm 0.05 \% \\
\delta^{18} \mathrm{O} \pm 0.08 \%\end{array}$} \\
\hline Blank & & $19 \pm 4 p p b^{g}$ & blank $<1 \%$ & \\
\hline External precision ${ }^{d}$ & & $\pm 10 \mathrm{ppb}$ & $\delta \mathrm{Ar} / \mathrm{N}_{2} \pm 0.3 \%$ & \\
\hline & & & $\delta \mathrm{O}_{2} \mathrm{~N}_{2} \pm 0.1 \%$ & \\
\hline Size of ice sample & & $12-20 \mathrm{~g}$ & & \\
\hline Method & $\begin{array}{l}\text { small crusher } \\
+\mathrm{GC}\left(\mathrm{CO}_{2}\right)\end{array}$ & $\begin{array}{l}\quad L G G E \\
\text { wet extraction } \\
+ \text { GC }\end{array}$ & \multirow[t]{4}{*}{ N/A } & \multirow[t]{4}{*}{ N/A } \\
\hline Blank & $<1 \mathrm{ppm}$ & $20 \pm 6 \mathrm{ppb}^{\mathrm{g}}$ & & \\
\hline External precision ${ }^{\mathrm{d}}$ & $\pm 3 \mathrm{ppm}$ & $\pm 10 \mathrm{ppb}^{\mathrm{g}}$ & & \\
\hline Size of ice sample & $40 \mathrm{~g}$ & $50 \mathrm{~g}$ & & \\
\hline Method & $\begin{array}{l}\text { microcrusher }{ }^{\mathrm{h}} \\
+\mathrm{IR}\end{array}$ & $\begin{array}{l}\quad \text { SIO } \\
\text { wet extraction } \\
+\mathrm{GC}\end{array}$ & \multirow[t]{4}{*}{ N/A } & \multirow[t]{4}{*}{ N/A } \\
\hline Blank & negligible & negligible & & \\
\hline External precision ${ }^{d}$ & $\pm 3 \mathrm{ppm}$ & $\pm 20 \mathrm{ppb}$ & & \\
\hline Size of ice sample & $4 \mathrm{~g}$ & $100 \mathrm{~g}$ & & \\
\hline Method & \multirow[t]{4}{*}{ N/A } & $\begin{array}{l}\quad \text { URI } \\
\text { wet extraction } \\
+ \text { GC }\end{array}$ & $\begin{array}{l}\text { wet extraction } \\
\text { mass spectrometry }\end{array}$ & $\begin{array}{l}\text { wet extraction } \\
\text { mass spectrometry }\end{array}$ \\
\hline Blank & & $15 \pm 6 \mathrm{ppb}$ & Blank $<1 \% o^{i}$ & Blank $<0.03 \% 0^{\mathrm{i}}$ \\
\hline External precision ${ }^{d}$ & & $\pm 15 \mathrm{ppb}$ & $\pm 1 \%$ & $\pm 0.03 \%$ \\
\hline Size of ice sample & & $35 \pm 3 \mathrm{~g}$ & $10 \mathrm{~g}$ & $10 \mathrm{~g}$ \\
\hline \multicolumn{5}{|c|}{$\begin{array}{l}\text { GC is gas chromatography. } \\
\text { a [Etheridge et al., 1988]. }\end{array}$} \\
\hline \multicolumn{5}{|c|}{$\begin{array}{l}\text { b [Etheridge et al., 1996]. } \\
\text { c [Etheridge et al., 1992; Pec } \\
\text { d External precision is defin } \\
\text { external precision is determinec } \\
\text { processing the standard/ice mix } \\
\text { are CSIRO, CSIRO Division of } \\
\text { Glaciologie et Geophysique de } \\
\text { e [Fuchs et al., 1993]. } \\
\text { [ [ [Moor and Stauffer, 1984]. } \\
\text { g Chappellaz et al. (manusc } \\
\text { h The microcrusher device }\end{array}$} \\
\hline
\end{tabular}

bubble close-off region [Craig et al., 1988; Schwander 1989; Sowers et al., 1989], and any in situ chemical reactions. Finally, although not discussed here, the age of the air in the ice must be determined [Schwander and Stauffer 1984; Schwander et al., 1988].

We undertook an intercalibration study among five laboratories currently analyzing trapped gases in ice cores (Table 1). The study consisted of two separate components. The first part was the analysis of reference air samples by each laboratory in order to compare their working standards. The second part of the study included analyses of ice from a 4.2-m section of the GISP2 " $F$ " ice core which was drilled in July 1991. The species that were measured in this study were $\mathrm{CO}_{2}, \mathrm{CH}_{4}$, the ${ }^{18} \mathrm{O} /{ }^{16} \mathrm{O}$ ratio of trapped $\mathrm{O}_{2}$, the ${ }^{15} \mathrm{~N} /{ }^{14} \mathrm{~N}$ ratio of trapped $\mathrm{N}_{2}, \mathrm{O}_{2} / \mathrm{N}_{2}$, and $\mathrm{Ar} / \mathrm{N}_{2}$. Each laboratory analyzed the occluded air in ice samples relative to their working standard. Analytical capabilities, blanks, and the external precision associated with each extraction procedure (defined below Table 1) are listed in Table 1. One specific objective of this intercalibration study was to investigate the apparent disagreement between the average glacial $\mathrm{CH}_{4}$ values measured by different laboratories on the GISP2 and the 
Table 2. Results of NOAA Analyses of Primary High Pressure Cylinders Used to Fill the 2-L Glass Flasks Which Were Distributed to All Labs for Analyses

\begin{tabular}{lcc}
\hline Cylinder No. & {$\left[\mathrm{CO}_{2}\right], \mathrm{ppmv}$} & {$\left[\mathrm{CH}_{4}\right]_{2}$, ppbv } \\
109923 & $356.1 \pm 0.06$ & $1488.2 \pm 3$ \\
114771 & $375.4 \pm 0.06$ & $1824.4 \pm 3$ \\
111836 & & $463.5 \pm 3$ \\
\hline
\end{tabular}

Greenland Ice Core Project (GRIP) ice cores from Summit, Greenland.

\section{Experimental Techniques}

\section{Calibrating the Working Standards in Each Laboratory}

For the first part of the study, samples of reference air were sent to each laboratory for analysis in 2-L glass flasks. Each glass flask was filled from one of three high-pressure cylinders that had been previously calibrated for $\mathrm{CO}_{2}$ and $\mathrm{CH}_{4}$ by the National Oceanic and $\Lambda$ tmospheric Administration/Climate Monitoring and Diagnostics Laboratory group (NOAA/CMDL) (Table 2). Note that the elemental and isotopic composition of $\mathrm{O}_{2}, \mathrm{Ar}$, and $\mathrm{N}_{2}$ were not determined in these cylinders by NOAA. At least one, but generally two, glass flasks (equipped with two LouwersHapertrm 0 to $9 \mathrm{~mm}$, viton O-ring valves), were filled to $1 \mathrm{~atm}$. at the University of Rhode Island (URI) laboratory and sent to each laboratory where they were analyzed for as many constituents as possible. To insure the integrity of the flask samples, the $\mathrm{CH}_{4}$ concentration was measured at URI immediately after being filled, as well as after the flasks had been analyzed and returned to the URI laboratory. Results suggest that the $\mathrm{CH}_{4}$ concentrations in the returned flasks were within $0.5 \%$ of those of the parent cylinder. We conclude from these results that the filling and subsequent analyses of the flasks did not compromise the $\mathrm{CH}_{4}$ composition to a measurable extent. While it may be possible that other constituents (i.e., $\mathrm{CO}_{2}, \mathrm{O}_{2}$, or $\mathrm{N}_{2}$ ) were compromised during the filling and subsequent analyses, our previous experience with these flasks suggests this is rather unlikely.

Analysis of a common air standard by each laboratory was necessary to calibrate working standards for the second part of the study, the ice-core analyses. As part of this comparison, 10 samples from the GISP2 short " $F$ " core (10 $\mathrm{cm}$ diameter) were selected between 116.18 and $120.33 \mathrm{~m}$. below surface $(\mathrm{mbs})$. Each sample was carefully inspected to insure there were no visible fractures in the ice that would have compromised the integrity of the trapped air. The age of the occluded air in this interval corresponds to 1817-1832 A.D. [Wahlen et al., 1991; Alley et al., 1993]. Fossil air from this period was chosen for the intercalibration because the $\mathrm{CO}_{2}, \mathrm{CH}_{4}$, and $\mathrm{N}_{2} \mathrm{O}$ content of the atmosphere was fairly stable before, during, and after the study period [Wahlen et al., 1991; Etheridge et al., 1992; Blunier et al., 1993; Etheridge et al., 1996]. Each $\sim 30-\mathrm{cm}$ piece of ice was split lengthwise, providing two sections of core from the same depth interval. The ice was divided among the laboratories such that two laboratories analyzed samples from the same $30-\mathrm{cm}$ interval.

\section{Extraction Methods}

Three methods have been developed to extract gases from ice: the wet, dry, and the sublimation techniques. The wet technique involves inserting an ice sample into an extraction vessel, evacuating the vessel, and then allowing the ice to melt in vacuo to liberate the trapped gases. This technique has been used to analyze constituents that are relatively insoluble and chemically stable in water $\left(\mathrm{CH}_{4}, \mathrm{O}_{2}, \mathrm{~N}_{2}\right.$, and $\mathrm{Ar})$. During a dry extraction, the trapped gases are liberated without melting the ice. This is accomplished by placing an ice sample into a stainless steel extraction vessel where the ice is mechanically crushed, grated, or milled into very small pieces to release the occluded air parcels. Finally, a sublimation method has been used to separate large quantities of air from ice for gas analyses. This technique employs a glass extraction vessel L.rough which infrared light is applied to heat the ice in vacuo to a temperature just below the melting point. The water vapor and liberated air is cryogenically removed from the sublimation vessel by cold traps [Wilson and Donahue 1989; Wilson and Donahue 1990; Wilson and Long this issue]

One major difference in these techniques is the extraction efficiency. The wet and sublimation extraction techniques liberate all air occluded in the bubbles, as well as any air dissolved in the ice matrix, resulting in extraction efficiencies which are generally higher than 99\%. Dry extraction methods do not release air from all trapped bubbles and probably do not liberate any air which may be dissolved in the ice matrix [Wilson and Long, this issue]. Extraction efficiencies for the crushing techniques are generally below 80\% [Zumbrunn et al., 1982; Barnola et al., 1983; Neftel et al., 1983]. The details of the extraction protocols used by the laboratories for various gases follow. The descriptions are general and intended to relay the pertinent aspects of the different techniques for comparative purposes. Further details can be found in the cited publications.

$\mathrm{CO}_{2}$ analyses. Of the five laboratories listed in Table 1 , four measure the $\mathrm{CO}_{2}$ concentration of trapped gases on a routine basis. Unfortunately the Bern laboratory (Physics Institute, University of Bern, (Bern)) was unable to participate in the $\mathrm{CO}_{2}$ intercalibration because they were in the process of rebuilding their extraction device at the time of this study. There are two reasons why a wet extraction technique cannot be used for $\mathrm{CO}_{2}$ analyses. First, $\mathrm{CO}_{2}$ is extremely soluble in water, making quantitative extraction via a melt/refreeze technique almost impossible. Second, $\mathrm{CO}_{2}$ may be produced in an extraction vessel if acidic aerosol species can attack carbonate dust particles. The probability of carbonate dust particles interacting with acidic aerosols is much higher when both species are suspended in a liquid medium.

The Commonwealth Scientific and Industrial Research Organization (CSIRO) employs a "cheese grater" extraction device in which large ice samples $(500-1500 \mathrm{~g}$ of ice at $-80^{\circ} \mathrm{C}$ ) are inserted into a cylinder of perforated stainless steel 
(perforations toward the inside of a cylinder suspended inside a vacuum container). The container is then evacuated before loading horizontally into a shaker device which oscillates back and forth, sliding the ice sample along the perforations. The ice-core sample is grated into very fine pieces (snow) which liberate the trapped gases. As soon as the ice has been grated, the air in the container is cryogenically transferred through a water trap $\left(-100^{\circ} \mathrm{C}\right)$ to a cold finger $(-18 \mathrm{~K})$. The air sample is warmed before the $\mathrm{CO}_{2}$ is separated from other constituents on a packed chromatography column, catalytically converted to $\mathrm{CH}_{4}$, and detected with a flame ionization detector [Etheridge et al., 1996].

The Scripps Institute of Oceanography (SIO) laboratory uses a microcrusher to liberate the gases trapped in small ice samples. The crusher (cooled to $-60^{\circ} \mathrm{C}(213 \mathrm{~K})$ ) contains a bed of tapered rods to crush the sample lightly to avoid pressure melting during extraction. The released air is rapidly condensed into a minisample tube cooled to $-243^{\circ} \mathrm{C}(30 \mathrm{~K})$. Standard air samples are introduced over the crushed ice and analyzed in an identical fashion. After transfer, the trap is warmed to $-60^{\circ} \mathrm{C}(213 \mathrm{~K})$ and the gas is mixed into an IR cell with a bellows assembly before the $\mathrm{CO}_{2}$ is measured with a diode laser tuned to $4.3 \mu \mathrm{m}$ (R-12) [Wahlen et al., 1991].

At the Centre National de la Recherché Scientifique Laboratoire de Glaciologie et Geophysique de l'Environnement (CNRS LGGE), a $\sim 40-\mathrm{g}$ ice sample is placed inside a stainless steel container with stainless steel ball bearings. After evacuation, the container is shaken vigorously to crush the ice into a very fine powder. The released gas is then expanded into a sample loop and injected into a gas chromatograph equipped with a thermal conductivity detector [Barnola et al., 1983].

The overall analytical precision of these dry extraction techniques for $\mathrm{CO}_{2}$ analyses is generally better than \pm 3 parts per million by volume. Uncertainties derive from difficulties in separating $\mathrm{CO}_{2}$ from $\mathrm{H}_{2} \mathrm{O}$ during the extraction, and from adsorption of $\mathrm{CO}_{2}$ to the walls of the extraction apparatus [Zumbrunn et al., 1982; Barnola et al., 1983; Wahlen et al., 1991]. The overall experimental $\mathrm{CO}_{2}$ blank is negligible.

$\mathrm{CH}_{4}$ analyses. All five laboratories measure the $\mathrm{CH}_{4}$ concentration of trapped gases in ice. Two laboratories use a dry extraction technique similar to that used for $\mathrm{CO}_{2}$ and the other three use a wet extraction technique (Table 1). At LGGE and URI, an icc sample is inserted into an extraction vessel, which is then sealed and evacuated to pressures below $1 \mathrm{mbar}$ (the approximate water vapor pressure over ice at $-20^{\circ} \mathrm{C}$ ). The vessel is then isolated and the ice melted, thcreby liberating the trapped gases into the headspace above the water. Next, the water sample is refrozen from the bottom of the vessel to the top. This process forces the dissolved air into the head space. The ice is then cooled to temperatures between -80 and $-110^{\circ} \mathrm{C}$ (URI) or $-50^{\circ} \mathrm{C}$ (LGGE) to reduce the water vapor pressure in the head space.

The SIO procedure begins with the introduction of $100 \mathrm{~g}$ of ice into a $200-\mathrm{mL}$ glass vessel sealed with a teflon O-ring before evacuation. The sample is allowed to melt before 50 $\mathrm{mL}$ of distilled/degassed water is introduced into the vessel in order to increase the total gas pressure in the headspace. The sample is then refrozen to $-10^{\circ} \mathrm{C}$ to force the dissolved air into the headspace. All three wet extraction techniques then allow the fossil air in the headspace to expand into a previously evacuated sample loop; the air is then injected into a gas chromatograph where the $\mathrm{CH}_{4}$ is detected by a flame ionization detector.
The remaining two laboratories use a dry extraction procedure to liberate the trapped gases. The CSIRO laboratory uses the same aliquot of air from the large crusher for analyses of both $\mathrm{CH}_{4}$ and $\mathrm{CO}_{2}$. In Bern, a small milling device is used to shave a 12 to $20 \mathrm{~g}$ ice sample to liberate the trapped gases. The gases are then trapped in a cryofocusing device (Porapak-Q ${ }^{\mathrm{m}}$ column, cooled to $-170^{\circ} \mathrm{C}$ ) and analyzed with a gas chromatograph equipped with a flame ionization detector [Blunier et al., 1993; Fuchs et al., 1993].

The experimental precision of the $\mathrm{CH}_{4}$ analyses is generally better than $2 \%$ of preindustrial atmospheric values (700 ppbv). Part of the uncertainty can be attributed to variables associated with the chromatography. The other source of uncertainty comes from the extraction procedure itsclf. Those procedures involving a "melt-refrecze" cycle to liberate $\mathrm{CH}_{4}$ tend to develop $\mathrm{CH}_{4}$ contamination that is proportional to the amount of time the ice sample remains in the liquid state, although the exact nature of this contamination is unclear. Multiple blank determinations at LGGE and URI infer a small and reproducible blank of $20 \pm 6$ ppbv and $15 \pm 6$ ppbv, respectively, indicating that the blank corrections can be made precisely. For those systems utilizing stainless steel bellows valves, a small $\mathrm{CH}_{4}$ contamination may result from $\mathrm{CH}_{4}$ outgassing from the bellows when the valve is opened or closed. Depending on the configuration and the tendency for $\mathrm{CH}_{4}$ to outgas from a specific valve, varying amounts of $\mathrm{CH}_{4}$ can be added to the sample [Chappellaz 1990].

The $\delta \mathrm{O}_{2} \mathrm{~N}_{2}, \delta \mathrm{Ar} / \mathrm{N}_{2}, \delta^{18} \mathrm{O}$, and $\delta^{15} \mathrm{~N}$ analyses. Both wet and dry extraction procedures were used to separate the trapped gases from the ice for $\mathrm{O}_{2}, \mathrm{Ar}$, and $\mathrm{N}_{2}$ analyses [Sowers et al., 1989; Leuenberger, 1992]. After the gases are separated from the ice, the fossil air sample is allowed to expand into a sample reservoir on a mass spectrometer. The sample is then analyzed against a reference air standard and the results are reported using the standard delta notation. The elemental and isotopic results are reported as deviations from a standard. The ${ }^{15} \mathrm{~N} /{ }^{14} \mathrm{~N},{ }^{18} \mathrm{O} /{ }^{16} \mathrm{O}$, and $\mathrm{Ar} / \mathrm{N}_{2}$ atmospheric ratios are extremely homogeneous and constant on millennial timescales. Therefore the atmosphere has been used as the primary standard for reporting the elemental and isotopic composition of $\mathrm{O}_{2}, \mathrm{Ar}$, and $\mathrm{N}_{2}$ in ice.

The $\mathrm{O}_{2} / \mathrm{N}_{2}$ ratio of the atmosphere fluctuates by as much as $0.16 \%$ on a seasonal basis due to photosynthesis and respiration [Keeling et al., 1996]. In addition, the atmospheric $\mathrm{O}_{2} \mathrm{~N}_{2}$ ratio has been decreasing throughout the last century because of $\mathrm{O}_{2}$ consumption associated with fossil fuel combustion and land use changes. The measured $\delta \mathrm{O}_{2} / \mathrm{N}_{2}$ decline is approximately $0.014 \%$ o/yr, while seasonal fluctuations in mid-high latitudes can be as large as $0.16 \%$ [Keeling and Shertz 1992]. Therefore, depending on when a working standard was calibrated for $\mathrm{O}_{2} \mathrm{~N}_{2}$, the resulting $\delta \mathrm{O}_{2} \mathrm{~N}_{2}$ values on fossil air could vary by as much as $0.2 \%$. However, because the analytical uncertainty associated with the $\mathrm{O}_{2} / \mathrm{N}_{2}$ analyses in this study is greater than $1 \%$, seasonal or interannual $\mathrm{O}_{2} \mathrm{~N}_{2}$ variations do not measurably affect the results in this study. The $\mathrm{O}_{2} / \mathrm{N}_{2}$ ratio of trapped air in ice is not influenced by seasonal changes in the atmosphere because of mixing via molccular diffusion in the firn above the bubble close-off region.

The overall analytical precision of the elemental and isotopic analyses is generally better than $2 \%$ and $\pm 0.04 \%$, respectively. Part of the uncertainty derives from the mass spectrometric analyses $( \pm 0.8 \%$ or the elemental and $\pm 0.03 \%$ o 
Table 3. Results of Analyses of 2-L Glass Flasks Which Were Filled From High Pressure Cylinders of Commercial Air and Distributed to All Laboratories

\begin{tabular}{|c|c|c|c|c|c|c|}
\hline \multirow[b]{2}{*}{ Cylinder ID/Lab } & \multicolumn{4}{|c|}{ Elemental Analyses $^{a}$} & \multicolumn{2}{|c|}{ Isotopic Analyses $^{a}$} \\
\hline & $\begin{array}{l}\mathrm{CO}_{2} \\
\text { ppmv }\end{array}$ & $\begin{array}{c}\mathrm{CH}_{4} \\
\mathrm{ppbv} \\
\end{array}$ & $\begin{array}{c}\mathrm{\delta O}_{2} / \mathrm{N}_{2} \\
\% \text { w.r.t. air }\end{array}$ & $\begin{array}{c}\delta \operatorname{Ar} / \mathrm{N}_{2} \\
\% \text { w.r.t. air }\end{array}$ & $\begin{array}{r}\delta^{18} \mathrm{O} \text { of } \mathrm{O}_{2} \\
\% \text { w.r.t. air }\end{array}$ & $\begin{array}{r}\delta^{15} \mathrm{~N} \text { of } \mathrm{N}_{2} \\
\% \text { w.r.t. air }\end{array}$ \\
\hline NOAA/CMDL Calib. & 375.4 & 1824.4 & & & & \\
\hline 114771/CSIRO & 375.5 & 1825.3 & & & & \\
\hline 114771/URI & N/A & N/A & $0.1 \pm 0.1$ & $0.2 \pm 0.15$ & $-0.13 \pm 0.02$ & $-0.06 \pm 0.02$ \\
\hline $114771 /$ SIO & $375.9 \pm 1.7(2)$ & $1825 \pm 9(5)$ & & & & \\
\hline 114771/LGGE & $376.9 \pm 0.8$ & $1858 \pm 7$ & & & & \\
\hline 114771/BERN & & $1844 \pm 5(14)$ & $-0.16 \pm 0.06$ & $0.29 \pm 0.4$ & $0.01 \pm 0.01$ & $-0.04 \pm 0.01$ \\
\hline NOAA/CMDL Calib. & 356.1 & 1488.2 & & & & \\
\hline 109923/CSIRO & 356 & 1484.5 & & & & \\
\hline 109923/URI & N/A & N/A & $0.0 \pm 0.1$ & $0.35 \pm 0.15$ & $-0.09 \pm 0.03$ & $-0.02 \pm 0.02$ \\
\hline 109923/SIO & $357.5 \pm 0.9(8)$ & $1495 \pm 9(5)$ & & & & \\
\hline 109923/LGGE & $357.3 \pm 0.4$ & $1521 \pm 3$ & & & & \\
\hline 109923/BERN & N/A & $1502 \pm 3(15)$ & $-0.47 \pm 0.14$ & $0.23 \pm 0.18$ & $0.02 \pm 0.01$ & $-0.03 \pm 0.01$ \\
\hline NOAA/CMDL Calib. & & 463.5 & & & & \\
\hline $111836 /$ CSIRO & & $463.8 \pm 1(6)$ & & & & \\
\hline $111836 / \mathrm{SIO}$ & & $475.5 \pm 7(10)$ & & & & \\
\hline $111836 / \mathrm{LGGE}$ & & $463.5 \pm 2(11)^{b}$ & & & & \\
\hline $111836 / \mathrm{BERN}$ & & $468.3 \pm 9(8)$ & & & & \\
\hline $111836 /$ URI & & $464.6 \pm 8(15)^{c}$ & & & & \\
\hline
\end{tabular}

\footnotetext{
a The values reported are the average values of all analyses. Uncertainties are \pm 1 sigma and the number of analyses are reported in parentheses. Values without parentheses are the average values obtained on a single flask or cylinder.

$\mathrm{b}$ The two glass flasks with air from the 111836 cylinder $\left(\mathrm{CH}_{4} \sim 464 \mathrm{ppb}\right)$ analyzed at LGGE were analyzed using a separate working standard which was previously calibrated to the NOAA scale.

${ }^{c}$ URI used the calibrated standards as their working standards. Analyses of the 114771 and 109923 cylinders are, by definition, equivalent to the NOAA values and therefore are not included in the table. The 111836 cylinder was analyzed against the 114771 and 109923 cylinder before the 111836 cylinder was calibrated at NOAA. The URI results on this cylinder are therefore reported.

Also included are the $\mathrm{CO}_{2}$ and $\mathrm{CH}_{4}$ values assigned to each high pressure cylinder by NOAA/CMDL. The $\delta \mathrm{O}_{2} / \mathrm{N}_{2}, \delta \mathrm{Ar} / \mathrm{N}_{2}, \delta^{18} \mathrm{O}$ of $\mathrm{O}_{2}$, and $\delta^{15} \mathrm{~N}$ of $\mathrm{N}_{2}$ values are given in permil with respect to (w.r.t.) air.
}

for the isotopic analyses). The elemental analyses also appear to be influenced by heterogeneities in the trapped gas composition, possibly related to small amounts of gas loss through small fractures in the ice that develop as the core relaxes after recovery from the ice sheet [Craig et al., 1988; Sowers et al., 1989; Bender et al., 1995].

\section{Intercalibration Results}

\section{Standard gases}

The results of the standard gas intercalibration are listed in Table 3. The $\mathrm{CO}_{2}$ analyses indicate that the concentrations of the working standards in all three laboratories are between 0.0 and $0.38 \%$ higher than the NOAA calibrated standards. The difference between the measured $\mathrm{CO}_{2}$ values on each air flask and the $\mathrm{CO}_{2}$ values assigned by NOAA/CMDL is negligible after considering the overall analytical uncertainty associated with the measurements themselves. This suggests that the working $\mathrm{CO}_{2}$ standards in all three laboratories are consistent with one another.

Analyses of the various $\mathrm{CH}_{4}$ working standards also agreed reasonably well (Table 4). $\mathrm{CSIRO}$ measured $\mathrm{CH}_{4}$ values which were indistinguishable from the NOAA values. The other three laboratories (LGGE, Bern, and SIO) analyzed $\mathrm{CH}_{4}$ levels which were $2.0 \%, 1.0 \%$, and $1.0 \%$, respectively, higher than the NOAA values. Because the URI laboratory uses the two cylinders as their working standards, their results are not reported.

Two laboratories (Bern and URI) were able to analyze the elemental and isotopic composition of $\mathrm{O}_{2}, \mathrm{~N}_{2}$, and $\mathrm{Ar}$ in the standard gas. The $\delta^{15} \mathrm{~N}$ of $\mathrm{N}_{2}$ results from the two laboratories

Table 4. Normalization Factors for Comparing Working Standards From Each Laboratoy With the NOAA/CMDL Scale

\begin{tabular}{lcc}
\hline & & \\
Laboratory & {$\left[\mathrm{CO}_{2}\right], \%$} & {$\left[\mathrm{CH}_{4}\right], \%$} \\
\hline CSIRO & 0.00 & 0.0 \\
SIO & 0.38 & 1.0 \\
LGGE & 0.37 & 2.0 \\
BERN & N/A & 1.0
\end{tabular}

Values reported are the deviations (in percent) with respect to the NOAA/CMDL values given in Table 1. The normalized values in Table 5 are calculated by dividing the measured value by the corresponding normalization factor listed above. 
Table 5. Results of $\mathrm{CO}_{2}$ and $\mathrm{CH}_{4}$ Analyses on GISP 2 Ice Between 116 and 121 Meters Below the Surface (mbs)

\begin{tabular}{|c|c|c|c|c|}
\hline \multirow[b]{2}{*}{ Depth.mbs/lab ID } & \multicolumn{2}{|c|}{ Normalized to NOAA/CMDL } & \multicolumn{2}{|c|}{ Uncorrected } \\
\hline & {$\left[\mathrm{CO}_{2}\right]$, ppmv } & {$\left[\mathrm{CH}_{4}\right], \mathrm{ppbv}$} & {$\left[\mathrm{CO}_{2}\right], \mathrm{ppmv}$} & {$\left[\mathrm{CH}_{4} 4\right], \mathrm{ppbv}$} \\
\hline $116.30-116.35 /$ URI & & $739(1)$ & & $739(1)$ \\
\hline 116.63-116.9/ CSIRO & $289.6(1)$ & $770.6(1)$ & $289.6(1)$ & $770.6(1)$ \\
\hline 116.7-116.75/ URI & & $737 \pm 6(2)$ & & $737 \pm 6(2)$ \\
\hline $117.02-117.04 / \mathrm{SIO}$ & $290.5 \pm 11(3)$ & & $291.6 \pm 11(3)$ & \\
\hline 117.09-117.11/ SIO & $303.6 \pm 11(3)$ & & $304.7 \pm 11(3)$ & \\
\hline $117.115-117.135 /$ SIO & $292.0 \pm 22(3)$ & & $293.1 \pm 22(3)$ & \\
\hline 117.28-117.33/ SIO & & $751 \pm 15(1)$ & & $759 \pm 15(1)$ \\
\hline 117.3-117.33/ URI & & $753 \pm 14(2)$ & & $753 \pm 14(2)$ \\
\hline $117.48-117.52 /$ LGGE & & $740 \pm 11(2)$ & & $755 \pm 11(2)$ \\
\hline 117.53-117.57/LGGE & & $741 \pm 10(1)$ & & $756 \pm 10(1)$ \\
\hline $117.6-117.65 /$ URI & & $754 \pm 10(2)$ & & $754 \pm 10(2)$ \\
\hline 118.00-118.33/ CSIRO & $291.5(1)$ & $763.4(1)$ & $291.5(1)$ & $763.4(1)$ \\
\hline 118.3-118.32/ BERN & & $762 \pm 1(3)$ & & $769 \pm 1(3)$ \\
\hline 118.407-118.453/ LGGE & & $734 \pm 7(2)$ & & $749.5 \pm 7(2)$ \\
\hline $118.42-118.444 / \mathrm{SIO}$ & $273.7 \pm 15(2)$ & & $274.7 \pm 15(2)$ & \\
\hline $118.45-118.48 / \mathrm{SIO}$ & $266.6 \pm 15(3)$ & & $267.6 \pm 15(3)$ & \\
\hline 118.453-118.483/LGGE & $281.8 \pm 2(1)$ & & $282.8 \pm 2(1)$ & \\
\hline $118.483-118.513 /$ LGGE & $291.5 \pm 2(1)$ & & $292.6 \pm 2(1)$ & \\
\hline $118.57-118.63 / \mathrm{SIO}$ & & $745 \pm 19(1)$ & & $753 \pm 19(1)$ \\
\hline 118.70-119.01/ CSIRO & $291.9(1)$ & $758.4(1)$ & $291.9(1)$ & $758.4(1)$ \\
\hline 118.72-118.74/ SIO & $256.1 \pm 23(2)$ & & $257.1 \pm 23(2)$ & \\
\hline $118.74-118.76 / \mathrm{SIO}$ & $249.3 \pm 3(3)$ & & $250.2 \pm 3(3)$ & \\
\hline 119.045-1 19.065/ SIO & $281.4 \pm 2(3)$ & & $282.4 \pm 2(3)$ & \\
\hline 119.17-119.23/ SIO & & $753 \pm 20(1)$ & & $761 \pm 20(1)$ \\
\hline 119.185-119.205/ SIO & $275.2 \pm 10(2)$ & & $276.2 \pm 10(2)$ & \\
\hline $119.22-119.27 / \mathrm{SIO}$ & & $747 \pm 20(1)$ & & $755 \pm 20(1)$ \\
\hline $119.27-119.33 /$ SIO & & $745 \pm 17(1)$ & & $753 \pm 17(1)$ \\
\hline 119.74-119.78/LGGE & & $736 \pm 7(2)$ & & $751 \pm 7(2)$ \\
\hline 119.76-119.80/LGGE & & $737 \pm 7(2)$ & & $752 \pm 7(2)$ \\
\hline 119.80-119.83/LGGE & $289.0 \pm 2(1)$ & & $290.1 \pm 2(1)$ & \\
\hline 119.83-119.86/LGGE & $288.9 \pm 3(1)$ & & $290.0 \pm 3(1)$ & \\
\hline 119.86-119.89/LGGE & $289.9 \pm 4(1)$ & & $291 \pm 4(1)$ & \\
\hline 119.89-119.92/LGGE & $294.4 \pm 3(1)$ & & $295.5 \pm 3(1)$ & \\
\hline $120.02-120.04 / \mathrm{SIO}$ & $279.4 \pm 1(2)$ & & $280.4 \pm 1(2)$ & \\
\hline $120.04-120.06 / \mathrm{SIO}$ & $281.6 \pm 10(3)$ & & $282.6 \pm 10(3)$ & \\
\hline $120.07-120.09 / \mathrm{SIO}$ & $288.6 \pm 0.1(2)$ & & $289.7 \pm 0.1(2)$ & \\
\hline $120.17-120.23 / \mathrm{SIO}$ & & $747 \pm 15(1)$ & & $755 \pm 15(1)$ \\
\hline $120.22-120.27 / \mathrm{SIO}$ & & $744 \pm 21(1)$ & & $754 \pm 21(1)$ \\
\hline Average normalized values & $283 \pm 13(21)$ & $748 \pm 10(20)$ & & \\
\hline
\end{tabular}

The $\mathrm{CO}_{2}$ and $\mathrm{CH}_{4}$ values listed have been corrected for procedural blanks listed in Table 1. Results in the second and third columns have been further corrected by normalizing to the NOAA/CMDL standard scale using the correction factors in Table 4 . None of the data have been corrected for gravitational fractionation. The magnitude of the correction is $-1.5 \mathrm{ppm}$ and $+2.7 \mathrm{ppb}$ for $\mathrm{CO}_{2}$ and $\mathrm{CH}_{4}$ respectively, based on an average $\delta^{15} \mathrm{~N}$ of $\mathrm{N}_{2}=0.32 \%$ o (Table 6 and equation (11) from Sowers et al., [1989]). Stated uncertainties are \pm 1 sigma.

were identical within the overall analytical uncertainty (Table 3). The $\delta^{18} \mathrm{O}$ results from URI were lower than Bern by $0.13 \pm 0.02 \%$. One possible explanation for this $\delta^{18} \mathrm{O}$ discrepancy involves the presence of substantial amounts of water vapor in some of the glass flasks which were used to transport aliquots of the URI working standards. Adsorption and/or isotopic exchange of water vapor with $\mathrm{O}_{2}$ may have compromised the isotopic composition of the standard air in the source of the mass spectrometer. The origin and concentration of the water vapor are unclear. The $\delta^{\mathrm{O}_{2} / \mathrm{N}_{2}}$ and $\delta^{A x} / N_{2}$ data from the two laboratories were consistent, although there does appear to be a slight $(0.4 \%$ ) discrepancy in the $\delta^{\mathrm{O}_{2}} / \mathrm{N}_{2}$ data with the URI values being higher than the Bern values. This latter difference could be due to previously mentioned difficulties in calibrating the $\delta^{O_{2} / N_{2}}$ of the working standard against present-day air.

\section{Analyses of the Trapped Gases in the GISP2 Ice Core}

$\mathrm{CO}_{2}$ and $\mathrm{CH}_{4}$ results on the fossil air extracted from the GISP2 ice core are included in Table 5 and illustrated in Figures 1 and 2, respectively. In addition to the raw data, we have calculated and included the results from each laboratory on the NOAA calibration scale, using the normalization 


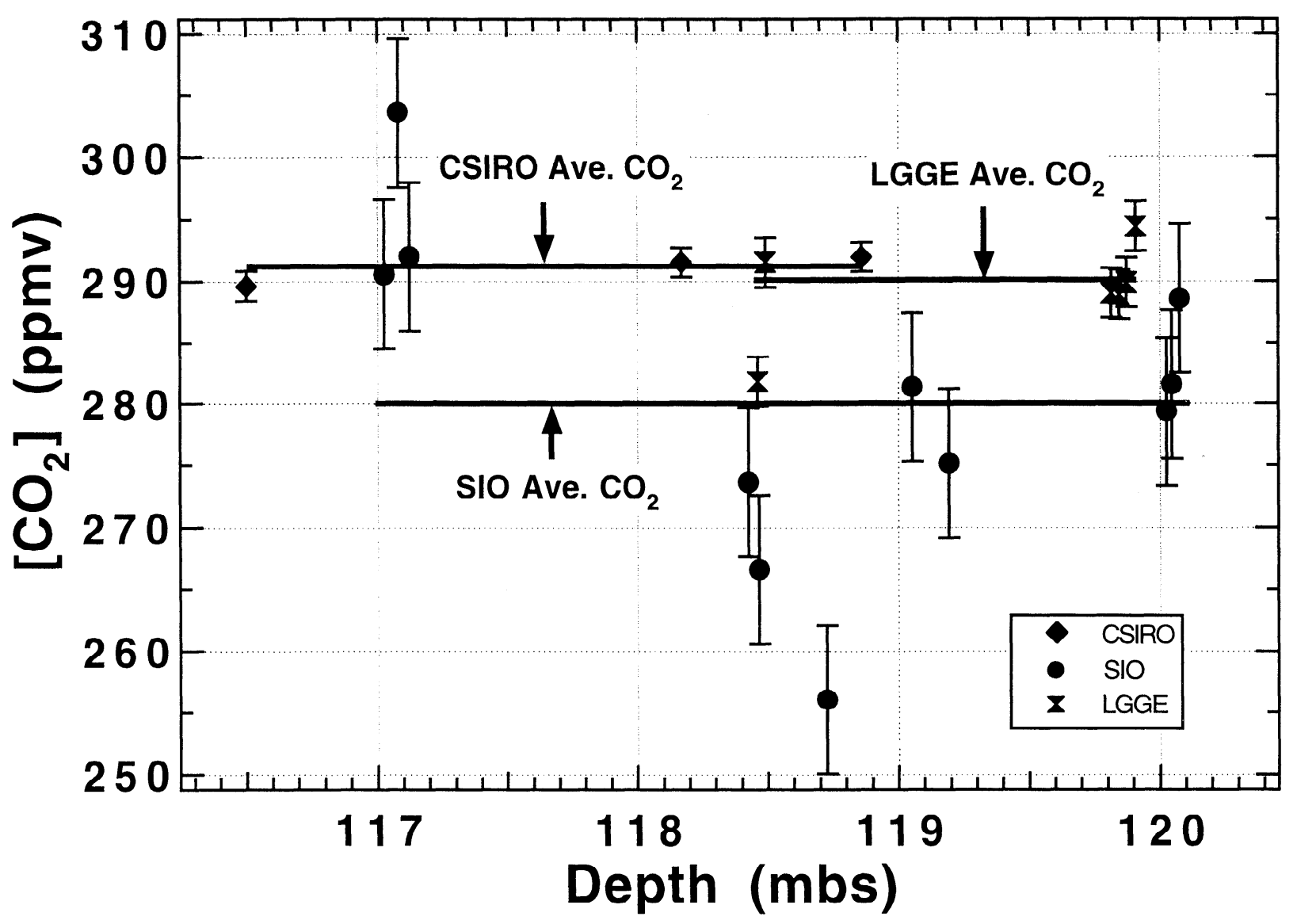

Figure $1, \mathrm{CO}_{2}$ results for the intercalibration ice. All data have been corrected for procedural blanks and normalized to the NOAA concentration scale using the normalization factors in Table 4 . All data are plotted with \pm 1 -sigma error bars. A horizontal line corresponding to the average value for each laboratory was drawn across the depth interval where the analyses were made.

factors in Table 4. All data in Table 5 have been corrected for blank values in Table 1 . In the case of $\mathrm{CO}_{2}$, the average concentration was $283 \pm 13$ ppmv for twenty one discrete depths. Note that the standard deviation about the mean of all 21 analyses $( \pm 13 \mathrm{ppmv})$ is considerably higher than the averaged external reproducibility of $\mathrm{CO}_{2}$ measured in ice by each laboratory $( \pm 6 \mathrm{ppmv})$. Normalized $\mathrm{CO}_{2}$ values measured at LGGE $(N=6)$ and CSIRO $(N=3)$ differed by 1.7 ppmv. The average $\mathrm{CO}_{2}$ value measured at $\mathrm{SIO}(N=12)$ was 11 ppmv lower than either LGGE or CSIRO. These results suggest that the $\mathrm{CO}_{2}$ concentration along the $4.2-\mathrm{m}$ section of intercalibration ice is not homogeneous.

In contrast, the normalized $\mathrm{CH}_{4}$ results from the intercalibration ice were mostly consistent. The average of 20 discrete samples was $748 \pm 10$ ppbv. This range of values is comparable to the external precision associated with the $\mathrm{CH}_{4}$ measurements, suggesting that the $\mathrm{CH}_{4}$ concentration in all intercalibration ice was constant. In all cases, LGGE provided the lowest average $\mathrm{CH}_{4}$ value (738 \pm 3 ppbv, $N=5$ ) (Figure 2). The Bern and CSIRO data (762 and 764 ppbv, respectively) agreed within their uncertainties and were both higher than the SIO and URI data (747 and $746 \mathrm{ppbv}$, respectively). It is noteworthy that the two laboratories using dry extraction techniques both generated mean $\mathrm{CH}_{4}$ values that were slightly higher ( 20 ppbv) than those laboratories using a wet extraction technique. This difference is larger than the external precision of the measurements and may be related to differences in the extraction efficiencies and/or errors in blank estimates during the period when the intercalibration ice was analyzed.

Analyses of the isotopic and elemental composition of $\mathrm{O}_{2}$, $\mathrm{N}_{2}$, and $\mathrm{Ar}$ in trapped air from the intercomparison ice were performed at two laboratories. URI and Bern (Table 6). The average $\delta{ }^{15} \mathrm{~N}$ values were $0.32 \pm 0.01 \%$ and $0.39 \pm 0.05 \%$ for URI and Bern, respectively. The difference between the mean values determined by the two laboratories $(0.07 \%$ ) is outside the $95 \%$ confidence limits for the two sets of analyses. The average $\delta^{18} \mathrm{O}$ values from URI were $0.12 \%$ o lower than Bern and slightly larger than the analytical uncertainties of the two laboratories. As the average $\delta^{18} \mathrm{O}$ values from the two laboratories were approximately twice the $\delta^{15} \mathrm{~N}$ values, the artifact appears to be mass dependent. We suspect that this artifact is related to the sample extraction protocol or analytical procedures in onc or both of the laboratories, although the precise origin is not clear. Because the artifact appears to be mass-dependent, the calculated ${ }^{18} \mathrm{O} /{ }^{16} \mathrm{O}$ ratio of paleoatmospheric $\mathrm{O}_{2}\left(\delta^{18} \mathrm{O}_{\mathrm{atm}}=\right.$ $\delta^{18} \mathrm{O}_{\text {measured }}-2 * \delta^{15} \mathrm{~N}_{\text {measured }}$ ) [Sowers et al., 1989] from the two sets of analyses are in complete agreement $\left(\delta^{18} \mathrm{O}_{\mathrm{itm}}=0.03\right.$ $\pm 0.01 \%$ ) .

The average $\delta^{\mathrm{O}_{2}} / \mathrm{N}_{2}$ and $\delta^{A x} / \mathrm{N}_{2}$ data from the two laboratories were also consistent with one another as well as with previous measurements on the GISP2 core [Bender et al., 1995]. There is a large amount of scatter in the elemental 


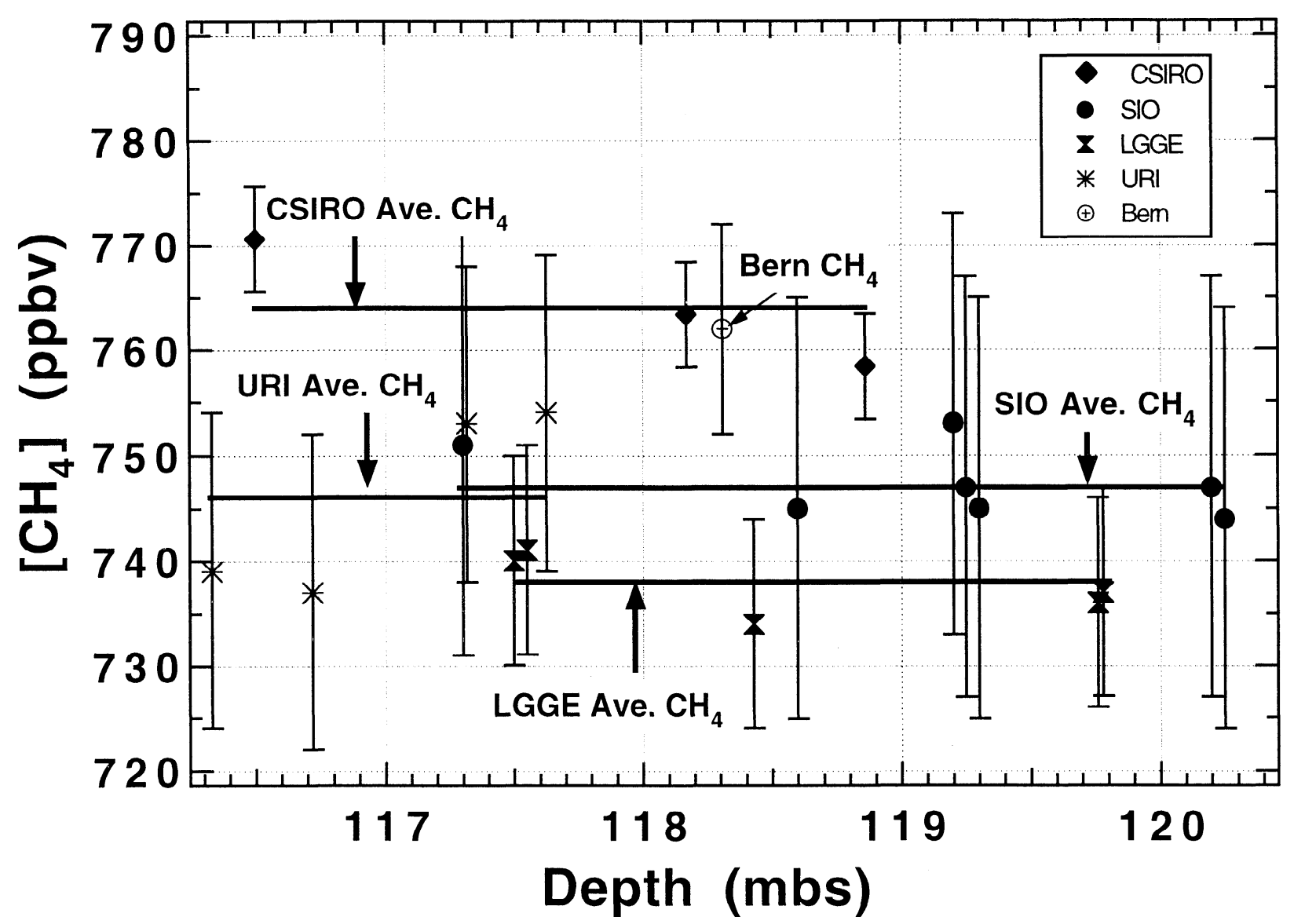

Figure 2, $\mathrm{CH}_{4}$ results for the intercalibration ice. All data have been corrected for procedural blanks and normalized to the NOAA concentration scale using the normalization factors in Table 4. All data are plotted with \pm 1 -sigma error bars. A horizontal line corresponding to the average value was drawn across the depth interval where the analyses were made. As there was only one depth measured by the Bern laboratory, no horizontal line is displayed.

data which has previously been attributed to heterogenieties in the bubble composition resulting from differential gas loss through microfractures [Bender et al., 1995].

\section{Discussion}

Heterogeneous Bubble Composition

One of the greatest uncertainties associated with this type of intercalibration is the degree to which the composition of the trapped air in the 4.2-m section of GISP2 ice (used for this study) is homogeneous. There are at least three possible causes of heterogeneous gas composition over centimeter spatial scales: (1) neighboring bubbles may be closed off at different depths in the firn-ice transition region, thereby trapping air of slightly different age, (2) compositional alterations may occur along microfractures in the ice whereby occluded air can escape as the ice relaxes,

Table 6. Elemental and Isotopic Composition of $\mathrm{O}_{2}, \mathrm{~N}_{2}$, and $\mathrm{Ar}$ in the GISP 2 Icc Core

\begin{tabular}{|c|c|c|c|c|}
\hline \multirow[b]{2}{*}{ Depth Interval / lab } & \multicolumn{2}{|c|}{ Elemental Analyses } & \multicolumn{2}{|c|}{ Isotopic Analyses } \\
\hline & $\begin{array}{l}\delta_{2} \mathrm{~N}_{2}, \\
\% \text { w.r.t. air } \\
\end{array}$ & $\begin{array}{l}\delta \mathrm{Ar} / \mathrm{N}_{2}, \\
\% \text { ow.r.t. air }\end{array}$ & $\begin{array}{l}\delta^{18} \mathrm{O} \text { of } \mathrm{O}_{2} \\
\% \text { w.r.t. air }\end{array}$ & $\begin{array}{l}\delta^{15} \mathrm{~N} \text { of } \mathrm{N}_{2} \\
\% \text { w.r.t. air }\end{array}$ \\
\hline 116.15-116.21/BERN & -3.8 & -2.5 & 0.75 & 0.34 \\
\hline 116.25-116.27/ URI & -3.5 & -9 & 0.65 & 0.31 \\
\hline 116.80-116.82/URI & $-5.8 \pm 9(2)$ & $9.5 \pm 0.9(2)$ & $0.66 \pm 0.02(2)$ & $0.32 \pm 0.006(2)$ \\
\hline 117.20-117.22/ URI & $-9.0 \pm 1.7(2)$ & $-9.0 \pm 1.7(2)$ & $0.73 \pm 0.05(2)$ & $0.33 \pm 0.01(2)$ \\
\hline 117.7-117.75/ URI & $-9.1 \pm 5.3(2)$ & $4.2 \pm 5.9(2)$ & $0.68 \pm 0.02(2)$ & $0.33 \pm 0.001(2)$ \\
\hline 119.73-119.83/BERN & -2.5 & -1.3 & 0.88 & 0.44 \\
\hline 120.01-120.11/ BERN & -1.1 & -0.7 & 0.78 & 0.39 \\
\hline
\end{tabular}
air

Depth values are given in meters below surface. All other valucs arc in permil with respect to (w.r.t.) present day 
and (3) chemical reactions within the ice may alter the trapped gas composition [Sowers et al., 1989; Anklin et al., 1995; Bender et al., 1995]. To address this potential heterogeneity, we split each core section into two equal halves. Each of the half-core sections was then shipped to a different laboratory for analyses so we could obtain two data sets from exactly the same depth interval. With the exception of $\mathrm{CO}_{2}, \delta^{\mathrm{O}_{2} / \mathrm{N}_{2}}$, and $\delta^{\mathrm{Ar}} / \mathrm{N}_{2}$, our results suggest that the gases are essentially homogeneous (within analytical uncertainty) throughout the $4.2-\mathrm{m}$ section. Variability in the $\delta^{\mathrm{O}_{2}} / \mathrm{N}_{2}$ and $\delta^{\mathrm{Ax}} / \mathrm{N}_{2}$ ratios has previously been documented in closely spaced samples from numerous cores [Sowers et al., 1989]. It is noteworthy that this artifact is probably not related to the $\mathrm{CO}_{2}$ variability in Greenland ice because the magnitude of the $\delta^{\mathrm{O}_{2}} / \mathrm{N}_{2}$ and $\delta^{\mathrm{A}} / \mathrm{N}_{2}$ variations is much smaller than the measured $\mathrm{CO}_{2}$ variability [Sowers et al., 1989].

\section{Extreme $\mathrm{CO}_{2}$ Variations}

Delmas [1993], Anklin et al. [1995], and Barnola et al. [1995] suggested that the high degree of variability associated with Greenland $\mathrm{CO}_{2}$ measurements may be related to $\mathrm{CO}_{2}$ liberation from carbonate dust due to dissolution by acid species in the ice or the in situ decomposition of organic acids. As the concentrations of carbonate dust, organic acids and hydrogen ions vary considerably over small spatial scales [Mayewski et al., 1993], it is entirely possible that the large $\mathrm{CO}_{2}$ variations we observed in Greenland ice were caused by in situ carbonate dissolution. We conclude therefore that it is impossible to make a detailed $\mathrm{CO}_{2}$ intercomparison using Greenland ice. Future efforts in this regard will use ice from an Antarctic ice core which has much lower dust and $\mathrm{H}^{+}$ concentrations and thus has $\mathrm{CO}_{2}$ concentrations that are both representative of the past atmosphere and homogeneous over larger spatial scales [Etheridge et al., 1996].

\section{Glacial $\mathrm{CH}_{4}$ Data From GISP2 and GRIP}

One important reason for performing a $\mathrm{CH}_{4}$ intercalibration was the apparent disagreement between the GISP2 and GRIP $\mathrm{CH}_{4}$ data during the last glacial pcriod $(17,000$ to 22,000 years before present (yr B.P.), Figure 3) [Chappellaz et al., 1993a, Brook et al., 1996]. We can think of three possible explanations for the apparent disagreement: (1) a calibration artifact between the two different $\mathrm{CH}_{4}$ working standards used in the two laboratories (LGGE and URI), (2) an unidentified $\mathrm{CH}_{4}$ blank associated with the analyses of glacial ice, or (3) nonlinearities in the flame ionization detector(s) used.

We present the $\mathrm{CH}_{4}$ data from the two ice cores covering the last 40,000 years along with the isotopic composition of the ice $\left(\delta^{18} \mathrm{O}_{\mathrm{ice}}\right)$ in Figure 3. GRIP $\mathrm{CH}_{4}$ data were generated by the LGGE and Bern laboratories [Blunier et al., 1993; Chappellaz et al., 1993; Blunier et al., 1995] and the GISP2 $\mathrm{CH}_{4}$ data were measured at URI [Brook et al., 1996]. We have constructed a common timescale by mapping the GRIP $\delta^{18} \mathrm{O}_{\text {ice }}$ record [GRIP Members 1993] into the GISP2 record [Grootes et al., 1993], which has been dated by counting annual layers throughout the GISP2 core [Alley et al., 1993; Meese et al., 1994]. The gas age-depth relation was derived by correcting for the ice age-gas age differences all along the cores using the protocol described by Brook et al. [1996]. After placing the two $\mathrm{CH}_{4}$ records on a common timescale, the data from the various laboratories were normalized to the NOAA scale using the normalization factors listed in Table 4. The normalization tends to exaggerate the $\mathrm{CH}_{4}$ discrepancy between the GRIP and GISP2 cores during the glacial period by $2 \%$. Note that the original GRIP data from Blunier et al. [1995] were lowered by 15 ppbv to account for a previously unidentified blank associated with the Bern milling device. The GRIP data from LGGE are directly from Chappellaz et al. [1993a].

Between 0 and $9 \mathrm{ka}$, all $\mathrm{CH}_{4}$ records agree. Prior to 9ka, URI values are consistently higher than corresponding GRIP values. The discrepancy is clearest during the Younger Dryas (11.7-13ka) and the peak of the last glacial period (between 17 and $23 \mathrm{ka}$ ) where URI values are 50 ppbv higher. Because the two cores are located 28 kilometers apart in very similar climatological settings, the $\mathrm{CH}_{4}$ records from the two cores should be identical.

One major difference between the URI and LGGE extraction protocols is the use of a stainless steel extraction vesscl at URI vcrsus a glass vessel at LGGE. Since the URI values are higher than LGGE during these periods (but not during the Holocene), it is conceivable that the elevated URI values before $9 \mathrm{ka}$ arc the result of an unexplained $\mathrm{CH}_{4}$ contamination associated with the stainless steel vessel which is not apparent in the younger samples. Owing to increasing hydrostatic pressure with depth in the ice sheet, the pressure in the bubbles increases until a threshold pressure is reached and the bubbles are slowly transformed into air hydrates, also know as clathrates [Gow et al., this issue]. The transformation in the GISP2 and GRIP cores occurs between 1300 and 1500 meters (7.4-9.3 ka), with all fossil air samples below this depth found in clathrate form. When samples of clathrated ice are allowed to melt, they tend to explode due to the rapid destabilization of the clathrates. One potential explanation for the elevated URI values in the clathrated ice involves enhanced $\mathrm{CH}_{4}$ outgassing from the stainless steel vessels as the ice shards from the exploding ice strike the walls. However, this explanation does not appear to hold during the Bolling and Older Dryas periods (13-17 ka) where URI and LGGE show good agreement in clathrated ice.

Because the discrepancy is largest when the measured values are below 550 ppbv, another explanation for the observed difference may involve nonlinear responses in one or both of the laboratories' flame ionization detectors. However, the analyses performed in all laboratories on the standard air with a nominal $\mathrm{CH}_{4}$ concentration of $463.5 \mathrm{ppbv}$ (NOAA scale) (Table 2) do not support this explanation.

Finally, it is also possible that the magnitude of the blank may depend on the concentration of $\mathrm{CH}_{4}$ in the sample. Here again, however, blank determinations using different standards with varying $\mathrm{CH}_{4}$ concentrations do not support this explanation. Both URI and LGGE have performed blank determinations using standard gases with $\mathrm{CH}_{4}$ concentrations below 489 ppbv. Neither laboratory demonstrated any dependence of the blank on the $\mathrm{CH}_{4}$ concentration.

At present, we do not have an acceptable explanation for the different $\mathrm{CH}_{4}$ values measured by URI and LGGE during the Younger Dryas and last glacial periods. Future efforts to resolve this issue will focus on analyses of glacial ice from the Vostok and other Antarctic ice cores. At Vostok, ice containing fossil air from between 18 and $26 \mathrm{ka}$ is found between 400 and $600 \mathrm{~m}$, which is well above the depth at which the bubbles begin to form clathrates. 


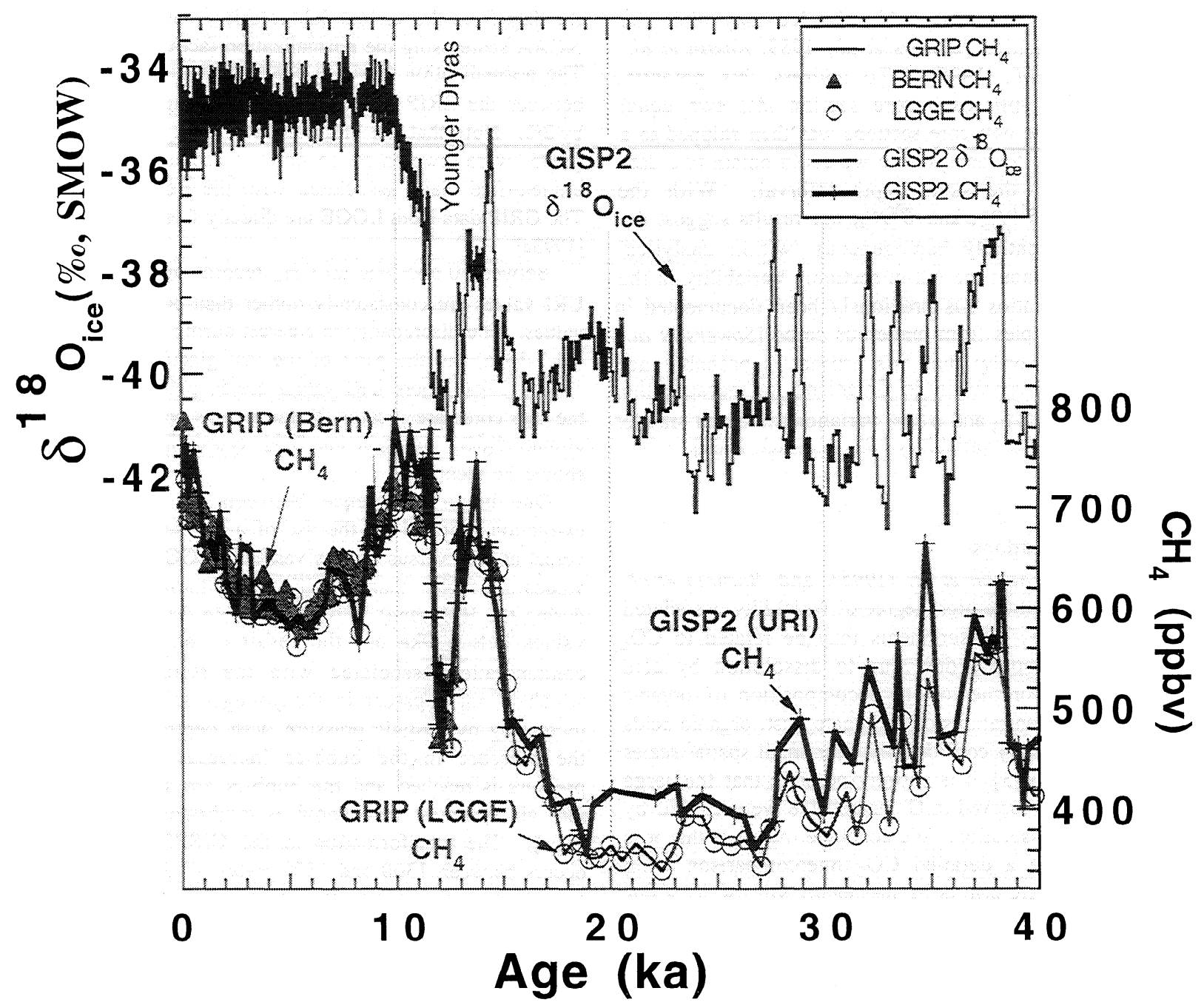

Figure 3, Isotopic temperature $\left(\delta^{18} \mathrm{O}_{\text {ice }}\right)$ [Grootes et al., 1993; Stuiver et al., 1995] and $\mathrm{CH}_{4}$ records from the GRIP [Blunier et al., 1993; Chappellaz et al., 1993; Blunier et al., 1995] and GISP2 [Brook et al., 1996] ice cores covering the last 40ka. The timescale for all records is that of the GISP2 core. All $\mathrm{CH}_{4}$ data have been corrected for blanks and normalized to the NOAA scale using normalization factors in Table 4 . None of the $\mathrm{CH}_{4}$ data have been corrected for gravitational fractionation. This correction is less than 3 ppbv and will not affect the difference between the two records as the correction is nearly the same for both cores. Note the excellent agrecment between the records between 0 and $9 \mathrm{ka}$. Prior to $9 \mathrm{ka}, \mathrm{URI}_{\mathrm{CH}}$ data appear to be $\sim 50$ ppbv higher than the corresponding GRIP data during cold periods.

\section{Conclusions}

The ice-core air extraction techniques have been shown to produce similar results for the ice tested (relatively shallow ice from a cold, moderate accumulation rate site in central Greenland). The $\mathrm{CO}_{2}$ standard scales at the various laboratories agreed with the NOAA scale within $\pm 0.38 \%$. For $\mathrm{CH}_{4}$ analyses, all laboratory standards agreed within $\pm 2 \%$. The average $\mathrm{CO}_{2}$ and $\mathrm{CH}_{4}$ values measured on the intercalibration ice (corrected for the slight differences in working standards) were $283 \pm 13 \mathrm{ppmv}$ and $748 \pm 10 \mathrm{ppbv}$, respectively. The $\mathrm{CO}_{2}$ data show excessive scatter which we believe is related to $\mathrm{CO}_{2}$-producing impurities in Greenland ice.

The $\mathrm{CH}_{4}$ results from the intercalibration ice showed subtle differences between the five laboratories which measured $\mathrm{CH}_{4}$. The standard deviation of all measurements about the mean $\mathrm{CH}_{4}$ value ( \pm 10 ppbv) is comparable to the overall analytical uncertainty for the $\mathrm{CH}_{4}$ measurements, suggesting that much of the observed scatter is the result of analytical uncertainties as opposed to artifacts associated with the extraction procedures. However, results from the dry extraction techniques (CSIRO and Bern) are, on average, 20 ppbv higher than the average results of the melt extraction techniques and are 26 ppbv higher than the mean LGGE results. These differences are slightly more than can be explained by the known measurement errors. While we have not been able to identify the cause of this discrepancy, we believe that the blanks we determined for some of the extraction procedures may be slightly underestimated for actual ice core samples. Therefore, when comparing $\mathrm{CH}_{4}$ records from different laboratories at high precision levels (i.c., $<20 \mathrm{ppbv}$ ), the interlaboratory differences in calibration scales and extraction procedures need be taken into account. 
The elemental and isotopic compositions of $\mathrm{O}_{2}, \mathrm{~N}_{2}$, and Ar trapped in the intercalibration ice were measured by two laboratories. The $\delta^{15} \mathrm{~N}$ of $\mathrm{N}_{2}$, the $\delta^{\mathrm{O}_{2}} / \mathrm{N}_{2}$, and the $\delta^{\mathrm{Ax}} / \mathrm{N}_{2}$ data from the two laboratories were consistent with one another within analytical uncertainties. The average $\delta^{18} \mathrm{O}$ of $\mathrm{O}_{2}$ data from URI were $0.12 \%$ lower than the Bern values. Estimates of the $\delta^{18} \mathrm{O}$ of the atmospheric $\mathrm{O}_{2}$ between 1817 and 1832 A.D. were in complete agreement $\left(\delta^{18} \mathrm{O}_{\mathrm{atm}}=0.03 \pm 0.01 \%\right.$ o $)$ with previous measurements.

Acknowledgments. T.A.S. and E.J.B. would like to thank M. Bender, J. Orchardo, T. Ellis, and M. Swanson for help in filling and analyzing calibration air and ice-core samples in URI. Support for T.A.S. was derived from NSF-OPP grant 93-21558. Ice core research at URI was supported by grants from the U.S. National Science Foundation. E.J.B. was also supported by a NOAA Climate and Global Change postdoctoral fellowship. D.M.E. thanks Ray Langenfelds, Darren Spencer, and Marco Lucarelli for their skilled operation and maintenance of laboratory instruments. Participation of D.M.E. in the intercomparison was supported in part by funding from the Australian Department of Environment, Sport and Territories (DEST) through the National Greenhouse Core Research Program.

\section{References}

Alley, R. B., D. Meese, C. A. Shuman, A. J. Gow, K. Taylor, M. Ram, E. Waddington, J. W. C. White and P. Mayewski, Abrupt accumulation increase at the Younger Dryas termination in the GISP2 ice core, Nature, 362, 527-529, 1993.

Anklin, M., J.-M. Barnola, J. Schwander, B. Stauffer and D. Raynaud, Processes affecting the $\mathrm{CO}_{2}$ concentrations measured in Greenland ice, Tellus, 47B, 461-470, 1995.

Barnola, J. M., D. Raynaud, A. Neftel and H. Oeschger, Comparison of $\mathrm{CO}_{2}$ measurements by two laboratories on air from bubbles in polar ice, Nature, 302, 401-413, 1983.

Barnola, J. M., D. Raynaud, Y. S. Korotkevich and C. Lorius, Vostok ice core provides 160,000-year record of atmospheric $\mathrm{CO}_{2}$, Nature, 329, 408-414, 1987.

Barnola, J. M., P. Pimienta, D. Raynaud and Y. S. Korotkevich, $\mathrm{CO}_{2}$ climate relationship as deduced from the Vostok ice core: A reexamination based on new measurements and on a reevaluation of the air dating, Tellus, Ser. B, 43b, 83-90, 1991.

Barnola, J. M., M. Anklin, J. Porcheron, D. Raynaud, J. Schwander and $\mathrm{B}$. Stauffer, $\mathrm{CO}_{2}$ evolution during the last millennium as recorded by Antarctic and Greenland ice, Tellus, Ser. B, 47b, 264 272,1995

Bender, M., T. Sowers and V. Lipenkov, On the concentrations of $\mathrm{O}_{2}$, $\mathrm{N}_{2}$ and $\mathrm{Ar}$ in trapped gases from ice cores, J. Geophys. Res., 100 $18,651-18,660,1995$.

Blunier, T., J. A. Chappellaz, J. Schwander, J. M. Barnola, T Desperts, B. Stauffer and D. Raynaud, Atmospheric methane record from a Greenland ice core over the last 1000 years, Geophys. Res. Lett., 20, 2219-2222, 1993

Blunier, T., J. Chappellaz, J. Schwander, B. Stauffer and D. Raynaud Variations in atmospheric methane concentration during the Holocene epoch, Nature, 374, 46-49, 1995.

Brook, E., T. Sowers and J. Orchardo, Rapid variations in atmospheric methane concentration during the past 110,000 years, Science, 273, 1087-1091, 1996.

Chappellaz, J., Etude du methane atmospherique au cors du dernier cycle climatique. A patir de l'analyse de l'air piege dans la glace Antartique, Univ. of Grenoble, Grenoble, France, 1990.

Chappellaz, J., T. Blunier, D. Raynaud, J. M. Barnola, J. Schwander and B. Stauffer, Synchronous changes in atmospheric $\mathrm{CH}_{4}$ and Greenland climate between 40 and 8 kyr BP, Nature, 366, 443445,1993

Chappellaz, J. A., I. Y. Fung and A. M. Thompson, The atmospheric $\mathrm{CH}_{4}$ increase since the last glacial maximum (1) Source estimates, Tellus, Ser. B. 45b, 228-241, 1993.

Craig, H., Y. Horibe and T. A. Sowers, Gravitational separation of gases and isotopes in polar ice caps, Science, 242, 1675-1678, 1988.

Delmas, R. J., A natural artifact in Greenland ice-core $\mathrm{CO}_{2}$ measurements, Tellus, Ser. B, 45b, 391-396, 1993.

Etheridge, D. M., G. I. Pcarman and F. Silva, Atmospheric trace-gas variations as revealed by air trapped in an ice core from Law Dome, Antarctica, Annals of Glaciology, 10, 28-33, 1988.

Etheridge, D. M., G. I. Pearman and P. J. Fraser, Changes in tropospheric methane between 1841 and 1978 from a high accumulation rate Antarctic ice core, Tellus, 44B, 282-294, 1992.

Etheridge, D. M., L. P. Steele, R. L. Langenfields, R. J. Francey, J.M. Barnola and V. I. Morgan, Natural and anthropogenic changes in atmospheric $\mathrm{CO}_{2}$ over the last 1,000 years from air in Antarctic ice and firn, J. Geophys. Res., 101, 4115-4128, 1996.

Fuchs, A., J. Schwander and B. Stauffer, A new ice mill allows precise concentration determination of methane and most probably also other trace gases in the bubble air of very small ice samples, J. of Glaciol., 39, 199-203, 1993.

Gow, A. J., d. M. Meese, R. B. Alley, J. J. Fitzpatrick, S. Anandadrishnan, G. A. Woods and B. C. Elder, Physical and structural properties of the Greenland Ice Sheet Project 2 ice core: A review, J. Geophys. Res., this issue.

Greenland Ice Core Project Members, Climate instability during the last interglacial period recorded in the GRIP ice corc, Nature, 364, 203-207, 1993.

Grootes, P. M., M. Stuiver, J. W. C. White, S. Johnsen and J. Jouzel, Comparison of oxygen isotope records from the GISP2 and GRIP Greenland ice cores, Nature, 366, 552-554, 1993

Keeling, R. F., S. C. Piper and M. Heimann, Global and hemispheric $\mathrm{CO}_{2}$ sinks deduced from changes in atmospheric $\mathrm{O}_{2}$ concentration, Nature, 381, 218-221, 1996.

Keeling, R. F. and S. R. Shertz, Seasonal and interannual variations in atmospheric oxygen and implications for the global carbon cycle, Nature, 358, 723-727, 1992.

Leuenberger, M., Isotopen-sowie Konzentrationsbestimmung and $\mathrm{CO}_{2}, \mathrm{~N}_{2} \mathrm{O}, \mathrm{O}_{2}, \mathrm{~N}_{2}$ in luftproben aus polarem eis, Ph.D. thesis, Univ. of Bern, Bern, Switzerland, 1992

Mayewski, P. A., L. D. Meeker, M. C. Morrison, M. S. Twickler, S. I Whitlow, K. K. Ferland, D. A. Meese, M. R. Legrand and J. P. Steffensen, Greenland ice core "signal" characteristics: An expanded view of climate change, J. Geophys. Res., 98, 12,839$12,847,1993$.

Meese, D., R. Alley, T. Gow, P. Grootes, P. Mayewski, M. Ram, K Taylor, E. Waddington and G. Zielinski, Preliminary depth-age scale of the GISP2 ice core, CRREL Spec. Rep. 94-1, Cold Reg. Res. and Eng. Lab., Hanover, N. H., 1994.

Moor, E. and B. Stauffer, Instruments and methods. A new dry extraction system for gases in ice, J. Glaciol., 30, 358-361, 1984.

Neftel, A., H. Oeschger, J. Schwander and B. Stauffer, Carbon dioxide concentration in Bubbles of natural cold ice, Journal of Physical Chemistry. 87, 4116-4120, 1983.

Neftel, A., F. Moor, H. Oeschger and B. Stauffer, Evidence from polar ice cores for the increase in atmospheric $\mathrm{CO}_{2}$ in the past two centuries, Nature, 315, 45-47, 1985.

Neftel, A., H. Oeschger, T. Staffelbach and B. Stauffer, $\mathrm{CO}_{2}$ record in the Byrd ice core 50,000-5,000 years BP, Nature, 33I, 609-611, 1988.

Pearman, G. I., D. Etheridge, d.e Silva, F. and P. J. Fraser, Evidence of changing concentrations of atmospheric $\mathrm{CO}_{2}, \mathrm{~N}_{2} \mathrm{O}$ and $\mathrm{CH}$ from air bubbles in Antarctic ice, Nature, 320, 1986.

Scholander, P. F., J. W. Kanwisher and D. C. Nutt, Gases in icebergs, Science, 123, 104-105, 1956.

Schwander, J., The transformation of snow to ice and the occlusion of gases, in The Environmental Record in Glaciers and Ice Sheets, edited by H. Oeschger and C.C. Langway, pp. 53-67, John Wiley, New York, 1989

Schwander, J. and B. Stauffer, Age difference between polar ice and the air trapped in its bubbles, Nature, 3II, 45-47, 1984

Schwander, J., B. Stauffer and A. Sigg, Air mixing in firn and the age of the air at pore close-off, Ann. Glaciol., 10, 141-145, 1988.

Sowers, T. A., M. L. Bender and D. Raynaud, Elemental and isotopic composition of occluded $\mathrm{O}_{2}$ and $\mathrm{N}_{2}$ in polar icc, J. Geophys. Res., $94,5137-5150,1989$.

Stauffer, B., A. Neftel and H. S. Oeschger J., C. C. Langway, H. Oeschger and W. Dansgaard, $\mathrm{CO}_{2}$ concentration in air extracted from Greenland ice samples, in Greenland Ice Core: Geophysics, Geochenistry, and the Environment, Geophys. Monogr. Ser. Vol. 
33, edited by C. C. Langway et al., pp 85-90, AGU, Washington, D. C. 1985.

Stauffer, B., E. Lochbronner, H. Oeschger and J. Schwander, Methane concentration in the glacial atmosphere was only half that of the preindustrial Holocene, Nature, 332, 812-814, 1988.

Stuiver, M., P. M. Grootes and T. F. Braziunas, The GISP2 $\delta^{18} \mathrm{O}$ climate record of the past 16,500 years and the role of the sun, ocean and volcanoes, Quat. Res., 44, 341-354, 1995.

Wahlen, M., D. Allen, B. Deck and A. Herchenroder, Initial measurements of $\mathrm{CO}_{2}$ concentrations (1530 to $1940 \mathrm{AD}$ ) in air occluded in the GISP II ice core from Central Greenland, Geophys. Res. Lett., 18, 1457-1460, 1991.

Wilson, $\mathrm{A}$. T. and d. F. Donahue, $\Lambda \mathrm{MS}$ carbon-14 dating of ice: progress and future prospects, Nuc. Inst. Method. Phys. Res., B52, 473-476, 1990.

Wilson, A. T. and D. J. Donahue, The recovery and dating of carbon dioxide in polar ice cores, Radiocarbon, 31, 579-584, 1989.

Wilson, A. T. and A. Long, New approaches to $\mathrm{CO}_{2}$ analysis in polar ice cores, J. Geophys. Res., this issue.

Zumbrunn, r., A. Neftel and $\mathrm{H}$. Oeschger, $\mathrm{CO}_{2}$ measurements on 1 $\mathrm{cm}^{3}$ ice samples with an IR laserspectrometer (IRLS) combined with a new dry extraction device, Earth Planet. Sci. Lett., 60 , 318-324, 1982.
J. -M. Barnola and J. Chappellaz, Laboratoire de Glaciologie et Geophysique de l'Environnement, CNRS, BP 96, 38402 St Martin d'Heres Cedex, France

T. Blunier, a. Fuchs, and M. Leuenberger Physics Institute, University of Bern, Sidlerstrasse 5, CH-3012, Bern, Switzerland

E. Brook, Department of Environmental Science,Washington State University, 14204 Salmon Creek Ave,Vancouver, WA 98686

B. Deck, M. Wahlen, and C. Weyhenmeyer, Scripps Institution of Oceanography, University of California, San Diego, La Jolla, 92093 0220

D. Etheridge, Division of Atmospheric Research, Commonwealth Scientific and Industrial Rescarch Organization, Aspendalc, Victoria 3195, Australia

T. Sowers, Department of Geosciences. Pennsylvania State University, University Park, PA 16802-2714. (e-mail: sowers@geosc.psu.edu)

(Received January 16, 1996; revised August 16, 1996; accepted January 4,1997 .) 